\title{
From State to Process: Defining Hydration
}

\author{
Erica T. Perrier ${ }^{a} \quad$ Lawrence E. Armstrong $^{\mathrm{b}}$ Michel Daudon ${ }^{\mathrm{c}}$ \\ Stavros Kavouras $^{d}$ Max Lafontan $^{e}$ Florian Lang $^{f} \quad$ François Péronnet $^{g}$ \\ Jodi D. Stookey ${ }^{\text {h }}$ Ivan Tack $^{i}$ Alexis Klein ${ }^{a}$

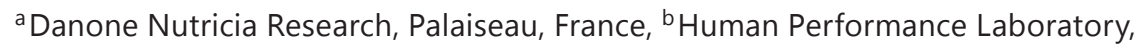 \\ Department of Kinesiology and Department of Nutritional Sciences, University of \\ Connecticut, Storrs, CT, USA, 'Service d'Explorations Fonctionnelles, Hôpital Tenon, Paris, \\ France, ${ }^{\mathrm{d}}$ Human Performance Laboratory, Department of Health and Human Performance, \\ University of Arkansas, Fayetteville, AR, USA, eINSERM/UPS UMR 1048-I2MC, Hôpital \\ Rangueil, Université Paul Sabatier, Toulouse, France, ${ }^{f}$ Institute of Physiology, University \\ of Tübingen, Tübingen, Germany, ${ }^{9}$ Département de kinésiologie, Université de Montréal, \\ Montréal, QC, Canada, h'Children's Hospital Oakland Research Institute, Oakland, CA, USA, \\ iService des Explorations Fonctionnelles Physiologiques et INSERM 1048 - Equipe 12, CHU \\ de Rangueil, Toulouse, France
}

\section{Key Words}

Hydration · Biological markers/urine · Body water · Drinking behavior · Vasopressin · Kidney

\section{Introduction}

Water is essential for nearly all biological processes, but throughout evolutionary history our ancestors survived periods of water insecurity such as drought or limited access to water safe for consumption. Thus, the survival of our species is due in part to the selection for a robust ability to regulate total body water (TBW) volume during periods of water insecurity. This is exemplified today in large population health and nutrition surveys, in which dramatic variations in water consumption are paired with a remarkable maintenance of normal plasma osmolality $\left(\mathrm{P}_{\mathrm{osm}}\right)$ (table 1), a marker of a normal hydration state (defined as the volume of TBW at a given time) [1]. The effect of an acute reduction in TBW volume (hypohydration or dehydration) on thermoregulation, cardiovascular function, and performance is well established $[2,3]$. Acute body water loss occurs regularly in persons exercising or working in hot and/or humid environments with restricted access to water, such as endurance athletes, 
Perrier et al.: From State to Process: Defining Hydration

Table 1. Mean serum osmolality by decile of total water intake in the Third National Health and Nutrition Examination Survey (NHANES III), 1988-1994 (source: U.S. Department of Health and Human Services, National Center for Health Statistics)

\begin{tabular}{|c|c|c|c|c|}
\hline \multirow[t]{2}{*}{ Decile } & \multicolumn{2}{|c|}{ Men (19-50 years) } & \multicolumn{2}{|c|}{ Women (19-50 years) } \\
\hline & $\begin{array}{l}\text { total water } \\
\text { intake, } \\
\text { l/day }\end{array}$ & $\begin{array}{l}\text { serum } \\
\text { osmolality, } \\
\text { mOsm/kg }\end{array}$ & $\begin{array}{l}\text { total water } \\
\text { intake, } \\
\text { l/day }\end{array}$ & $\begin{array}{l}\text { serum } \\
\text { osmolality, } \\
\text { mOsm/kg }\end{array}$ \\
\hline 1 & 1.7 & 279 & 1.2 & 277 \\
\hline 2 & 2.3 & 279 & 1.7 & 277 \\
\hline 3 & 2.7 & 281 & 2.0 & 277 \\
\hline 4 & 3.0 & 280 & 2.3 & 276 \\
\hline 5 & 3.3 & 280 & 2.6 & 277 \\
\hline 6 & 3.7 & 280 & 2.9 & 277 \\
\hline 7 & 4.1 & 280 & 3.3 & 277 \\
\hline 8 & 4.7 & 280 & 3.7 & 278 \\
\hline 9 & 5.6 & 280 & 4.3 & 277 \\
\hline 10 & 7.9 & 280 & 6.2 & 277 \\
\hline
\end{tabular}

military personnel, and some factory workers $[4,5]$. In contrast, as far as we know, there is no evidence for sustained chronic dehydration in the general population, i.e. a reduction of TBW volume below what appears to be a normal level (approximately $73 \%$ of fat-free mass (FFM) in adults [6]). However, recent evidence suggests that in the general population, the long-term effects of a low hydration process (defined as the volume of water added to and removed from the TBW pool each day; also known as TBW turnover) may have significant detrimental health consequences [7, 8], and this has so far received too little attention. We believe that in the interest of public health policy and awareness, there are some advantages and likely few disadvantages to maintaining TBW with a moderately higher, rather than lower, TBW turnover. It is time to shift the focus away from the hydration state (which is robustly defended over a wide range of TBW turnover) and widen the focus to include the hydration process, which varies widely between persons and possibly in a single individual from day to day.

\section{Hydration as a State}

In a mild environment (i.e. comfortable heat, solar load, and humidity), and with unrestricted access to safe drinking water, TBW expressed as percent body mass varies in direct proportion to differences in percent body fat (fig. 1). In fact, in adults, TBW is maintained at about $73 \%$ of FFM [6]; thus, individuals with a higher percent body fat have a lower relative TBW volume (expressed as a proportion of total body mass). For this reason, on average, men have a higher \%TBW than women, and \%TBW tends to decline with age as \%FFM decreases [9]. TBW may transiently increase or decrease in acute states of hyperhydration (e.g. binge drinking) or dehydration during exercise or work in hot environments, respectively. However, apart from exceptional circumstances which may require medical attention and, if not properly treated, can be fatal, these changes are transitory. Despite acute challenges to TBW homeostasis, the volume of the TBW pool is generally maintained at its normal level by continually adjusting water losses to water gains. This precise and continuous regulation of the hydration state occurs in situations of low to high daily water turnover, i.e. across differences in the hydration process. 
Perrier et al.: From State to Process: Defining Hydration

Fig. 1. \%TBW varies as a function of body composition. The constant relationship between TBW and FFM (TBW $=\sim 0.73 \times$ FFM in adults) explains why lean individuals have a higher \% TBW than those who are overweight or obese, why men generally have a higher \%TBW than women, and why \%TBW tends to decrease with age.

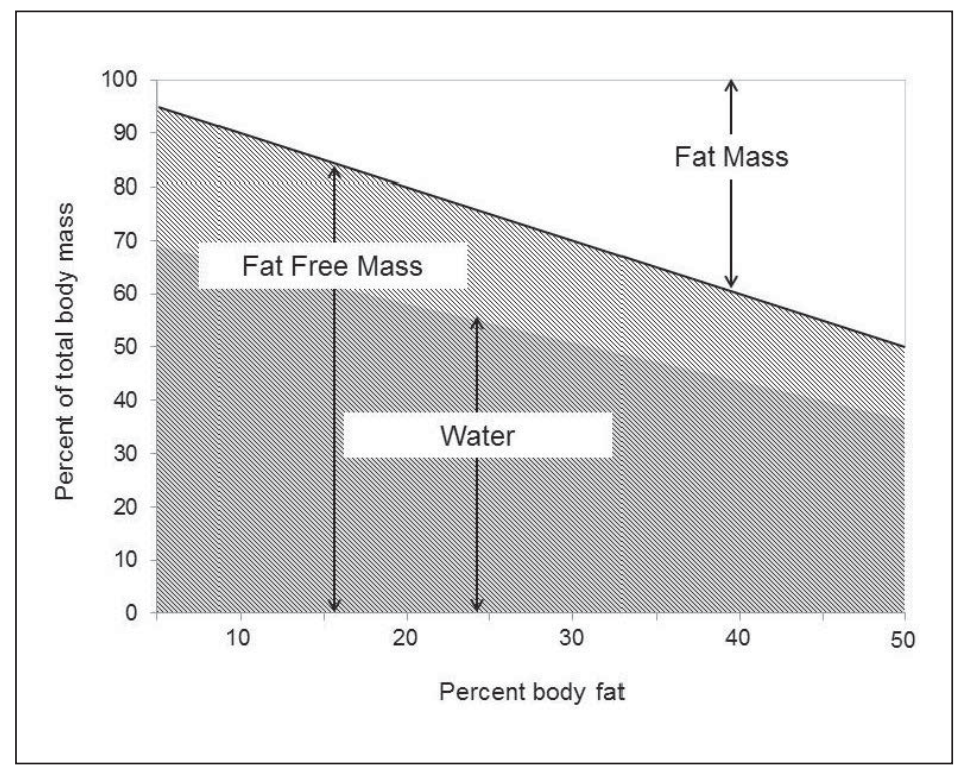

\section{Hydration as a Process}

In increasing order of volume, metabolic water production, water supplied in food, and water in fluids are the three sources of body water gain. Metabolic water production is proportional to energy expenditure and in most conditions accounts for only a small fraction of total water gain (about 250-400 ml/day [10]). The water content of food is highly variable and difficult to track on a day-to-day basis, and accounts for approximately $20-30 \%$ of total water intake $[11,12]$. Thus, the majority of total water intake occurs through drinking. Drinking is also the only source of water intake which is regulated through the sensation of thirst, in part triggered by a reduction in TBW and/or an increase in $\mathrm{P}_{\mathrm{osm}}$, and which can be voluntarily increased to compensate for large water losses.

As for losses from the body water pool, which include water loss in respiration, in transdermal evaporation, in feces, and in sweat and urine, the latter are the two largest and most variable routes of water disappearance. The production of sweat is dictated by the need to maintain body temperature and, in subjects engaged in sustained exercise in hot and humid environments, can result in large water losses and an acute reduction in TBW volume along with an increase in $\mathrm{P}_{\text {osm }}$ (i.e. hyperosmotic hypovolemia). In this situation and in all situations when the maintenance of TBW volume or plasma osmolality is challenged, the regulation of urine volume is the most effective mechanism available to try to match water loss to water gain.

This regulation is accomplished through an exquisitely sensitive and powerful feedback mechanism which detects small changes (1\% or less [13]) in $\mathrm{P}_{\text {osm }}$ and dramatically modifies water excretion in urine. In situations in which water is lost from the body water pool, or during water restriction, the resulting increase in $\mathrm{P}_{\text {osm }}$ stimulates osmoreceptors located in the hypothalamus. This triggers the release of the hormone arginine vasopressin (AVP, also known as the antidiuretic hormone (ADH)) from the nearby posterior pituitary [13]. AVP release can further be stimulated by decreases in central blood volume and distension of large central capacitance vessels, including the right atrium, which are associated with the reduction in TBW volume. AVP is the primary actor on V2 receptors in the kidney, increasing water reabsorption from the collecting ducts, and thus reducing water excretion in urine, concen- 
trating urine, conserving body water, and restoring $\mathrm{P}_{\text {osm }}$ and plasma volume to their normal value. In contrast, in a situation in which $\mathrm{P}_{\text {osm }}$ drops below and/or right atrial volume increases above its normal value, the secretion of AVP is reduced to very low levels. This leads to a decrease in water reabsorption from the collecting ducts and increased diuresis (increased volume of dilute urine), which restores normal $\mathrm{P}_{\text {osm }}$ and blood volume. This mechanism is both very sensitive and powerful, with the ability to concentrate urine up to approximately $1,200 \mathrm{mOsm} / \mathrm{kg}$ in individuals with normal kidney function [14], or to dilute urine to as low as $50 \mathrm{mOsm} / \mathrm{kg}$ [15]. The effectiveness of this mechanism explains why in large population samples, $\mathrm{P}_{\text {osm }}$ remains remarkably constant from the lowest to the highest deciles of reported daily water intake [16] (table 1). Thus, the normal hydration state can be maintained despite large differences in the hydration process, with very high or low water intake and loss, and high or low TBW turnover.

\section{Hydration State versus Hydration Process: Importance for Health}

We are not aware of any evidence showing that in healthy subjects, a moderate increase of water intake and TBW turnover are associated with health problems, acutely or in the long term. There are, however, important exceptions: For instance, in ultra-endurance events, overdrinking and inappropriate secretion of AVP may result in exercise-associated hyponatremia (EAH) [17]. In contrast, a low water intake and TBW turnover appears to be a factor in the development of some acute and chronic health problems. Low water intake has been repeatedly shown to be a risk factor in the development of primary and secondary kidney stone disease $[18,19]$, and a simple recommendation for patients to increase water intake can produce significant reductions in stone recurrence [20]. In addition, low water intake and low urine output have been linked to a more rapid decline in kidney function and an increased risk of chronic kidney disease $[8,21]$. Some evidence also suggests a relationship between low water intake and the development of hyperglycemia [22], and plasma hypertonicity may accelerate the progression from hyperglycemia to diabetes [23]. Some of the detrimental acute and long-term effects of low water intake, such as the development of kidney stones, can be readily attributed to the production of small urine volumes with a high osmolality, which is an inevitable consequence of a low water turnover. However, the effects of low water intake and low turnover on the kidney may reach far beyond the resulting low urine output and may reflect consequences of the 'antidiuretic effort' imposed on this organ by the high concentrations of AVP which are required to maintain an adequate hydration state. High levels of AVP may also unfavorably modify the clinical course of autosomal dominant polycystic kidney disease [24]. In addition, high concentrations of AVP may have detrimental effects on other organs and functions, as this hormone is suspected of playing a role in hypertension [25]. Among multiple other effects, AVP down-regulates the formation of the membrane protein and hormone klotho [26], which has been shown in mice to be a powerful inhibitor of aging and of the development of multiple age-related disorders [27].

Taken together these observations suggest that in terms of health benefits, both shortand long-term, maintaining a high TBW turnover by drinking more water is a definite advantage. The alternate choice, i.e. a low water intake and reduced body water turnover, will not jeopardize hydration state, TBW volume, or $\mathrm{P}_{\text {osm }}$ thanks to the ability of the kidney to concentrate urine. However, this is achieved at the cost of a high concentration of AVP which not only imposes a high antidiuretic effort to the kidney but also appears detrimental for several other functions and organs in the long term. 
Perrier et al.: From State to Process: Defining Hydration

Fig. 2. Deciles of total fluid intake of a 24-hour urine osmolality and b 24-hour urine volume in a sample of French adults [30]. Shaded bars represent the range of values between the 25 th and 75 th percentile, while the point represents the mean.

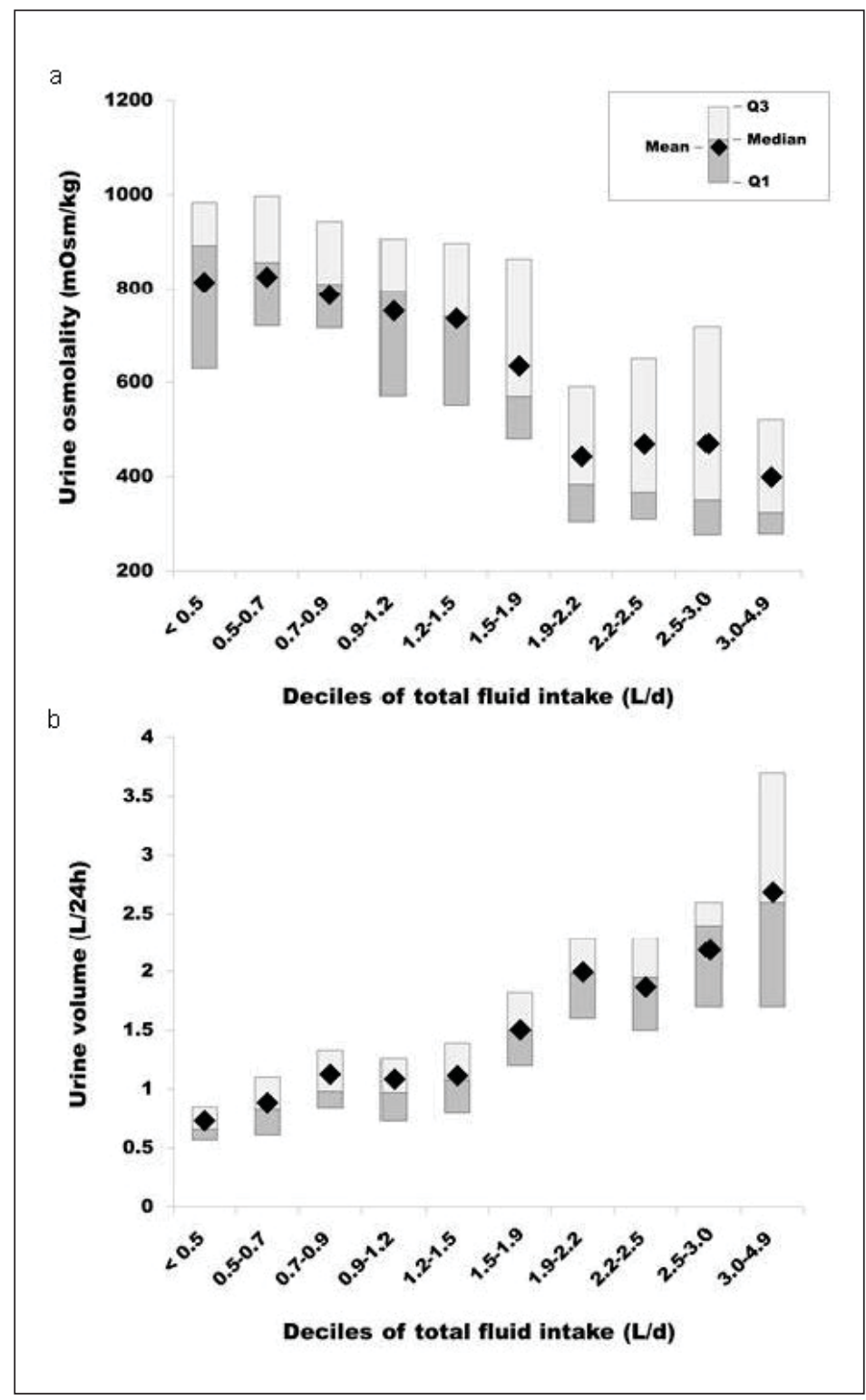

\section{Biomarkers of the Hydration Process}

As $\mathrm{P}_{\text {osm }}$ is tightly regulated, it remains virtually constant despite changes in fluid intake [28] as well as in some situations of dehydration [29]. This parameter reflects the hydration state which is well defended over a wide range of water intake and TBW turnover, thanks to the sensitive and efficient $\mathrm{P}_{\text {osm }}$-AVP antidiuresis feedback loop. As a consequence, it is only in situations of rapid, acute change in TBW volume that $\mathrm{P}_{\text {osm }}$ is an effective hydration marker. In most circumstances, the relevant variable to evaluate the hydration process of a subject or a population is the amount of water added to the body water pool and removed from this pool each day, i.e. TBW turnover.

Body water turnover is difficult to measure but fortunately can be accurately tracked by using simple characteristics of urine (fig. 2), whose concentration and volume reflect the antidiuretic effort of the kidney and thus are markers of the involvement of the $\mathrm{P}_{\mathrm{osm}}$-AVP 
antidiuretic loop in the control of urine production and the defense of $\mathrm{P}_{\mathrm{osm}}$. Four urinary variables, i.e. volume, osmolality, specific gravity, and color, shed light on the invisible but potent actions of AVP. Urinary hydration biomarkers have been shown to respond rapidly to changes in daily fluid intake [28], and two of them (specific gravity and color) can be measured in field environments, which make them the methods of choice as biomarkers to follow day-to-day changes in the hydration process.

Thus, mounting evidence suggests that the hydration process may be more important than the hydration state in the context of long-term health. While water has been called the most essential nutrient [31,32], water needs for optimal hydration have not been precisely nor consistently defined. Intake recommendations (estimated average requirements and dietary reference intakes) for most nutrients are based upon the amount necessary for metabolic and physiological function and the prevention of specific symptoms or disorders. In contrast, dietary reference intakes for water continue to be based upon population median consumption, in spite of the potential links to health and disease. The assumptions underlying water intake reference values have been that i) the hydration state, as measured by $\mathrm{P}_{\text {osm }}$, can be maintained through low or high TBW turnover, but also that ii) the hydration state is indicative of adequate intake for health. Unfortunately, intake surveys demonstrate that in the general population with easy access to water, a substantial proportion, while likely in an adequate hydration state, does not ingest the amounts of water indicative of a hydration process which may confer some reduction in disease risk. With respect to exactly how much water is enough, there is no universally accepted threshold for what represents the adequacy of the hydration process. However, evidence suggests that higher daily water intake impacts upon a number of chronic health outcomes. As there are some advantages and likely few disadvantages to maintaining TBW with a higher, rather than lower, TBW turnover, a plentiful daily water intake should be encouraged as a simple and effective health behavior.

\section{Disclosure Statement}

ETP and AK are employees of Danone Nutricia Research. LEA, MD, SK, ML, FL, FP, JS, and IT are occasional consultants for Danone Nutricia Research.

\section{References}

1 Horswill CA, Janas LM: Hydration and health. Am J Lifestyle Med 2011;5:304-315.

-2 Cheuvront SN, Carter R 3rd, Sawka MN: Fluid balance and endurance exercise performance. Curr Sports Med Rep 2003;2:202-208.

-3 Bardis CN, Kavouras SA, Arnaoutis G, Panagiotakos DB, Sidossis LS: Mild dehydration and cycling performance during 5-kilometer hill climbing. J Athl Train 2013;48:741-747.

4 Oppliger RA, Bartok C: Hydration testing of athletes. Sports Med 2002;32:959-971.

5 Peiffer JJ, Abbiss CR: Thermal stress in North Western Australian iron ore mining staff. Ann Occup Hyg 2013; 57:519-527.

6 Wang Z, Deurenberg P, Wang W, Pietrobelli A, Baumgartner RN, Heymsfield SB: Hydration of fat-free body mass: review and critique of a classic body-composition constant. Am J Clin Nutr 1999;69:833-841.

7 Manz F, Wentz A: The importance of good hydration for the prevention of chronic diseases. Nutr Rev 2005; 63:S2-S5.

-8 Strippoli GF, Craig JC, Rochtchina E, Flood VM, Wang JJ, Mitchell P: Fluid and nutrient intake and risk of chronic kidney disease. Nephrology (Carlton) 2011;16:326-334.

-9 Meeuwsen S, Horgan GW, Elia M: The relationship between BMI and percent body fat, measured by bioelectrical impedance, in a large adult sample is curvilinear and influenced by age and sex. Clin Nutr 2010;29: 560-566.

10 Raman A, Schoeller DA, Subar AF, Troiano RP, Schatzkin A, Harris T, Bauer D, Bingham SA, Everhart JE, Newman AB, Tylavsky FA: Water turnover in 458 American adults 40-79 yr of age. Am J Physiol Renal Physiol 2004;286:F394-F401.

11 Institute of Medicine: Dietary Reference Intakes for Water, Potassium, Sodium, Chloride, and Sulfate. Washington, DC, National Academies Press, 2004. 
$\$ 12$ European Food Safety Authority: Scientific opinion on dietary reference values for water. EFSA J 2010;8: 1459-1506.

13 Verbalis JG: Disorders of body water homeostasis. Best Pract Res Clin Endocrinol Metab 2003;17:471-503.

14 Miles BE, Paton A, De Wardener HE: Maximum urine concentration. Br Med J 1954;2:901-905.

15 Guyton AC, Hall JE: Regulation of extracellular fluid osmolarity and sodium concentration; in Guyton AC, Hall JE (eds): Textbook of Medical Physiology, ed 11. Philadelphia, Elsevier, 2006, pp 348-364.

16 U.S. Department of Health and Human Services NCfHS: Third National Health and Nutrition Examination Survey (NHANES III), 1988-1994.

17 Knechtle B, Gnadinger M, Knechtle P, Imoberdorf R, Kohler G, Ballmer P, Rosemann T, Senn O: Prevalence of exercise-associated hyponatremia in male ultraendurance athletes. Clin J Sport Med 2011;21:226-232.

18 Curhan GC, Willett WC, Knight EL, Stampfer MJ: Dietary factors and the risk of incident kidney stones in younger women: Nurses' Health Study II. Arch Intern Med 2004;164:885-891.

19 de la Gueronniere V, Le Bellego L, Jimenez IB, Dohein O, Tack I, Daudon M: Increasing water intake by 2 liters reduces crystallization risk indexes in healthy subjects. Arch Ital Urol Androl 2011;83:43-50.

-20 Borghi L, Meschi T, Amato F, Briganti A, Novarini A, Giannini A: Urinary volume, water and recurrences in idiopathic calcium nephrolithiasis: a 5-year randomized prospective study. J Urol 1996;155:839-843.

21 Clark WF, Sontrop JM, Macnab JJ, Suri RS, Moist L, Salvadori M, Garg AX: Urine volume and change in estimated GFR in a community-based cohort study. Clinical J Am Soc Nephrol 2011;6:2634-2641.

-22 Roussel R, Fezeu L, Bouby N, Balkau B, Lantieri O, Alhenc-Gelas F, Marre M, Bankir L: Low water intake and risk for new-onset hyperglycemia. Diabetes Care 2011;34:2551-2554.

23 Stookey JD, Pieper CF, Cohen HJ: Hypertonic hyperglycemia progresses to diabetes faster than normotonic hyperglycemia. Eur J Epidemiol 2004;19:935-944.

24 Wang CJ, Grantham JJ, Wetmore JB: The medicinal use of water in renal disease. Kidney Int 2013;84:45-53.

25 Zhang X, Hense HW, Riegger GAJ, Schunkert H: Association of arginine vasopressin and arterial blood pressure in a population based sample. J Hypertens 1999;17:319-324.

-26 Tang C, Pathare G, Michael D, Fajol A, Eichenmuller M, Lang F: Downregulation of Klotho expression by dehydration. Am J Physiol Renal Physiol 2011;301:F745-F750.

27 Kuro-o M: Klotho, phosphate and FGF-23 in ageing and disturbed mineral metabolism. Nat Rev Nephrol 2013; 9:650-660.

28 Perrier E, Demazieres A, Girard N, Pross N, Osbild D, Metzger D, Guelinckx I, Klein A: Circadian variation and responsiveness of hydration biomarkers to changes in daily water intake. Eur J Appl Physiol 2013;113:21432151.

29 Armstrong LE, Maughan RJ, Senay LC, Shirreffs SM: Limitations to the use of plasma osmolality as a hydration biomarker. Am J Clin Nutr 2013;98:503-504.

30 Perrier E, Klein A, Guelinckx I, Armstrong LE: Biological variation in urinary and salivary hydration biomarkers under conditions of ad-libitum fluid intake. Med Sci Sports Exerc 2013;45:343.

31 Manz F, Wentz A, Sichert-Hellert W: The most essential nutrient: defining the adequate intake of water. J Pediatr 2002;141:587-592.

32 Kavouras SA, Anastasiou CA: Water physiology: essentiality, metabolism, and health implications. Nutrition Today 2010;45:S27-S32. 